This article has been scanned by iThenticat No plagiarism detected

Volume 3, Issue 5, October 2021

p. 202-212

\title{
TOWARDS A REHABILITATION OF THE HAJJAJLINGUISTIC COMPONENT IN ISLAMIC SPEECH THOUGHT -THROUGH THE WRITINGS OF TAHA ABDEL- RAHMAN
}

http: //dx.doi.org/10.47832/2757-5403.5-3.18

\begin{abstract}
:
Taha Abd al-Rahman is considered one of the Arab scholars who had a clearimprint in Islamic the ological thought, through the system aticrenewal project that plays a pivotalrole in renewing the cognitive contents of theology as the productive machine, and the renewal of the latter addsvitality and novelty to the civilizational role that was occupied by science Islamicrhetoric in defending religion and values, through methodological features adopted by Taha Abdul Rahman to restore consideration for verbal rationality and for its Hajji and Dialogue approach.
\end{abstract}

Key words: Argument, Theology, Taha Abdel Rahman, Rehabilitation.

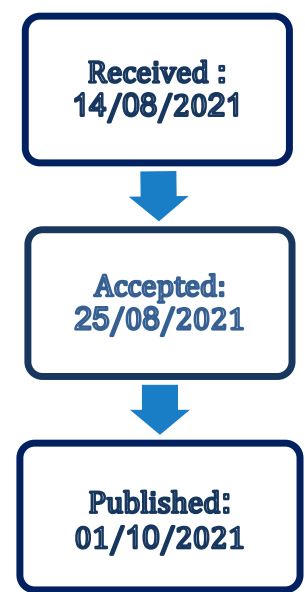

\footnotetext{
${ }^{1}$ Researcher, Emir Abd El Kader University, Algeria, https://orcid.org/0000-0002-2834-1048

${ }^{2}$ Researcher, Ez-Zitouna University, Tunisia, hibabenathmane3425@gmail.com, https: //orcid.org/0000-0001-7624-835
}

Copyright (C) Published by IJHER Journal, www.ijherjournal.com Rimar Academy, Fatih, Istanbul, 34093 Turkey 


\title{
"نحو إعادة الاعتبار للمكون الحجاجي اللغوي في الفكر الكلامي الإسلامي"

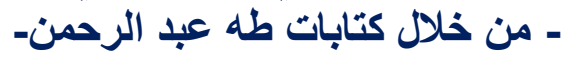

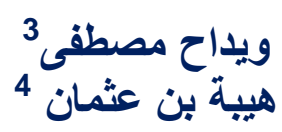

\begin{abstract}
الملخص المص
يعتبر طه عبد الرحمن من الدارسين العرب الذين كانت لهم بصمة جليّة في تجديد التراث

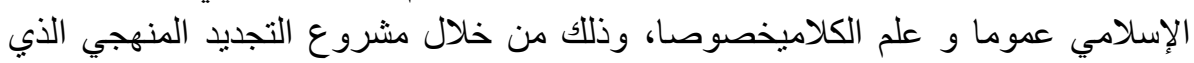

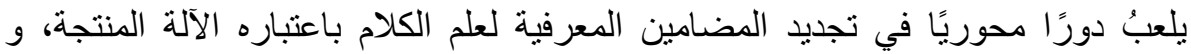

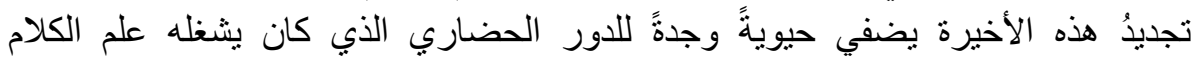

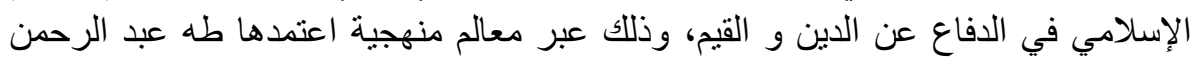

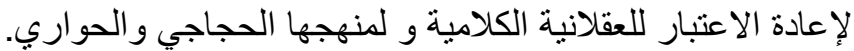

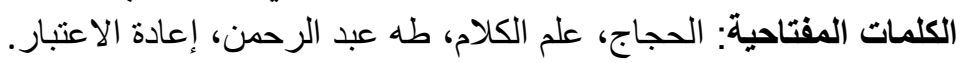

المقدمة:

لا مندوحة أن علم الكلام الإسلامي قد لعب دورا أساسيا في عرض العقيدة الدينية والدفاع عنها أمام الاستفزازات التي

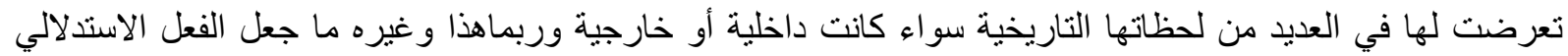

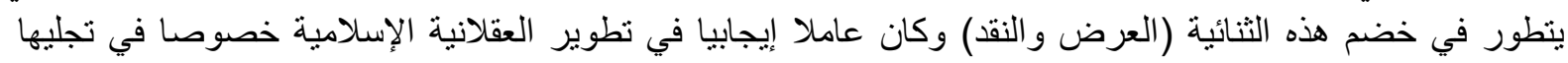

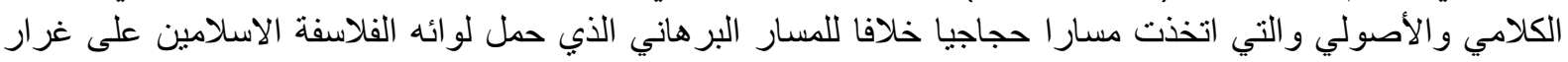

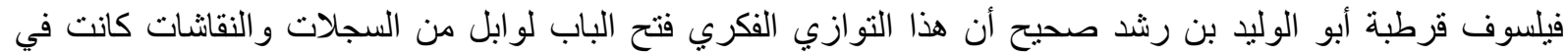

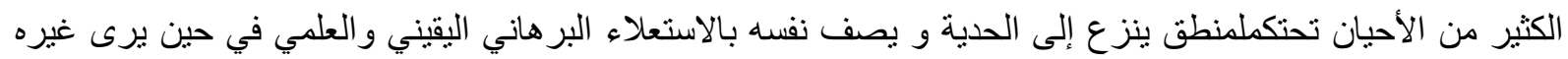

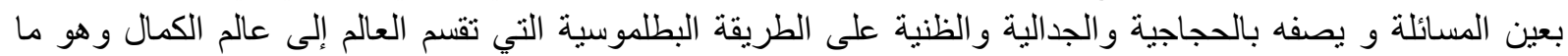
فوق القمر فللك و عالم الكون و الفساد وهو ما تحت القمر فتكون الحقيقة الفلسفية حقيقة كاملة برهانية ويقينية وتكون الحقيقة

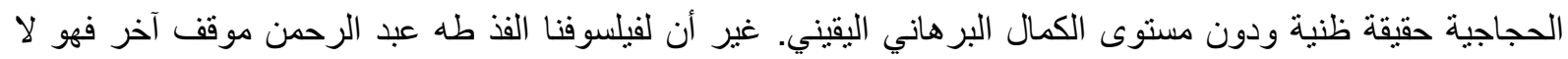

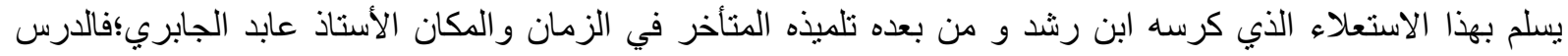

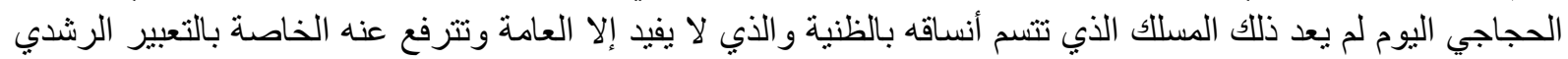

ثم إن صاحب "البلاغة الجديدة" شاييم بيرلمان -Chal̈m perlema-

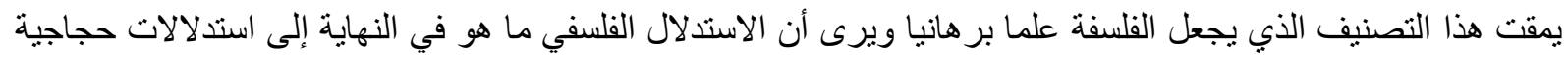

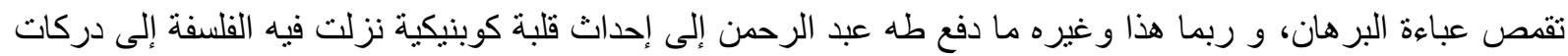

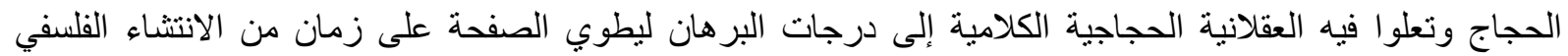

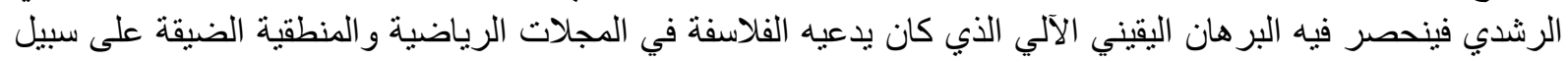

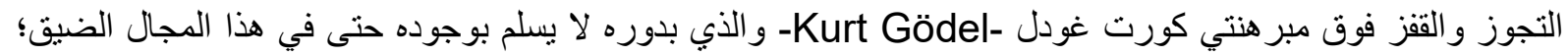

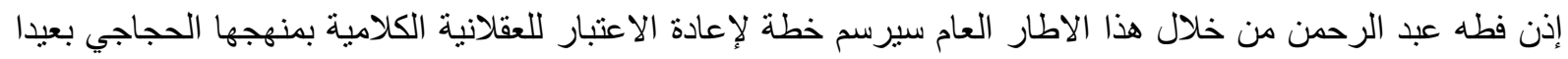

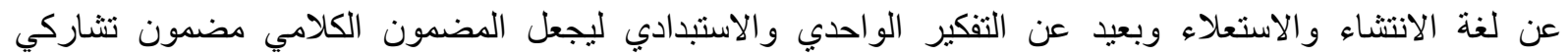

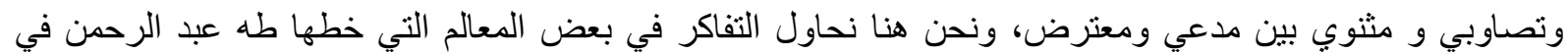
مدونته في هذا المجال الفكري الو وناسع. ومن خلال هذه الوريقات البحثية سنحاول الإجابة عن إثنكال يلوح في الأفق مفاده أنه إذا سلمنا أن التجديد المنهجي يلعب دورا محوريا في تجديد المضامين المعرفية لأي علمما، فما هي أهم المعالم المنهجية التي اختطها القية القريحة الطهائية 


\section{TOWARDS A REHABILITATION OF THE HAJJAJLINGUISTIC COMPONENT \\ IN ISLAMIC SPEECH THOUGHT -THROUGH THE WRITINGS OF TAHA ABDEL- \\ RAHMAN}

لإخر اج الفكر الكلامي من لحظات السبات والتوقف التي يعيشها، وما هي الخطة التي اعتمدها لإعادة الاعتبار للعقلانية

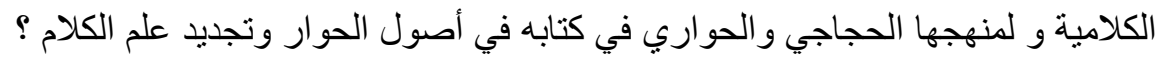

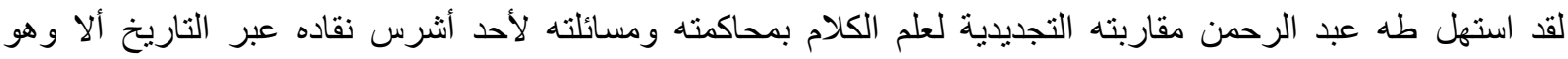

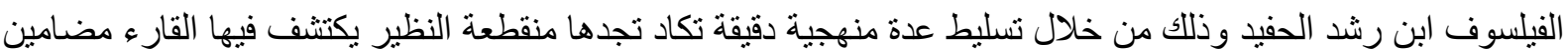

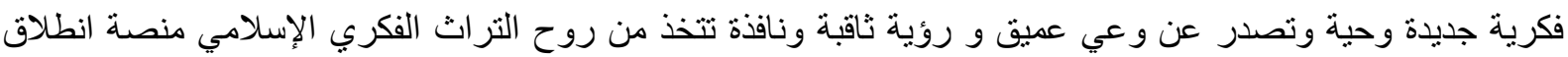
لها دون إيغال في فروع هذا العلم النفيس وذللك لعدم تشتيت القارء في حو اشي هو في غنى عنها، فئه فئه عبد الرحمن يحاول

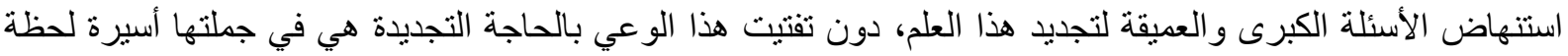

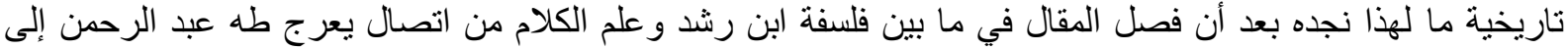

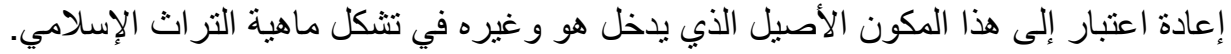

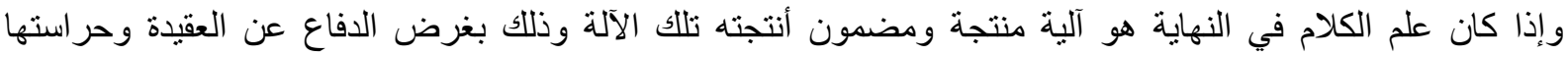
بعرض مضامينها وبحراستها من المخالف الناقم عليها؛كان لزاما أن التجديد المنهجي حتما سيكون تجديدا مضموني الني

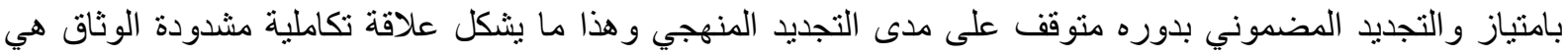

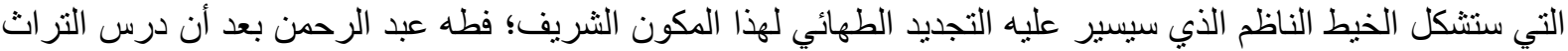

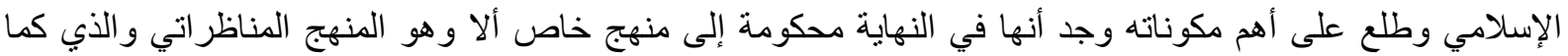

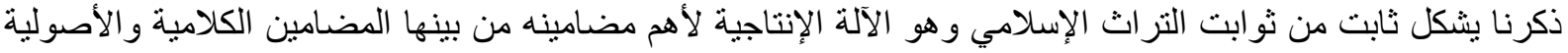
و الفقهية وغير ها من المعارف و العلوم؛ غير أنه في نظر طه يعتبر الدرس الكلامي الإسلامي أحد أهم تجليات الفاعلية لهذا

المنهج.

وطه عبد الرحمن في إطار مشروعه التجديد لعلم الكلام أعاد الاعتبار لهذا العلم وخصوصـا أمام الاستفزاز الذي سلطه

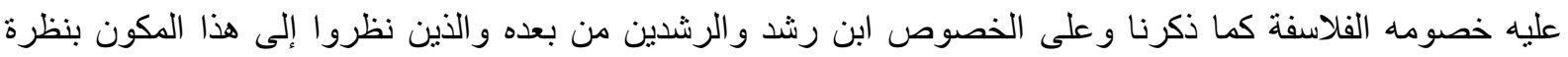

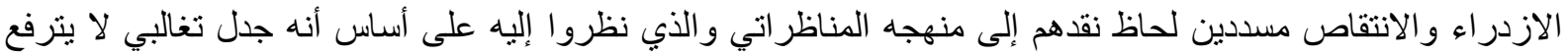

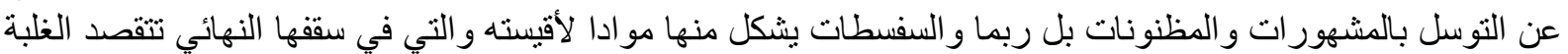

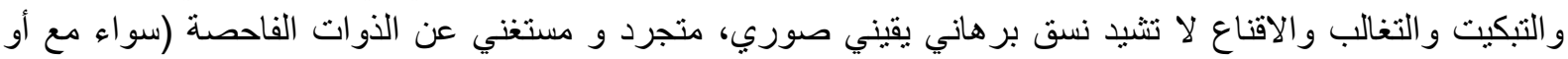
ضد)؛ غير أن هذا النقد رأى فيه طه استفزازا و عسفا قافزا على الحقيقة وهو متهما إياه بالتجزيئية المفرطة التي في

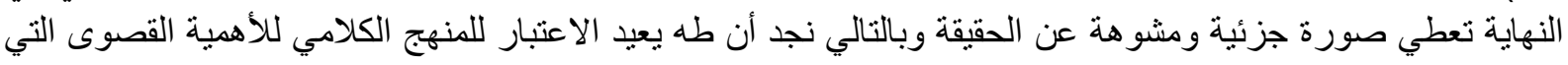

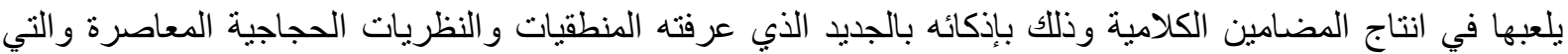
سيثكل منها ومن غير ها من المعطيات لينطلق في إنشاء ورشة جديدة لدفاع عن الدين ومسائلة الحداثة الغربية وهذا ماتيا

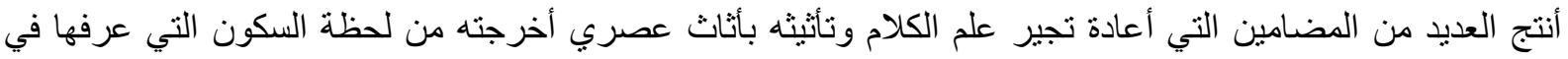
فترة من فتر اته ليستعيد شبابه إتمام لنقانتته الر اهنة.

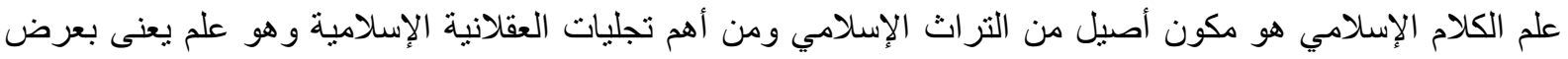
العقيدة الإسلامية ونقد المخالف لها أو بالأحرى حراستها من كل تشويه قد يمسها ومن الأشهر التعريفات لهذا العلم النفيس الإنس

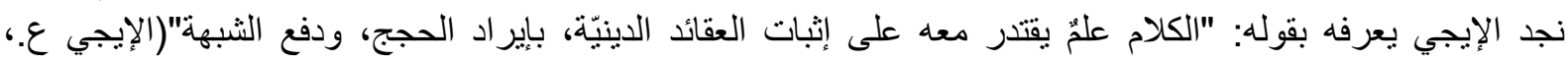

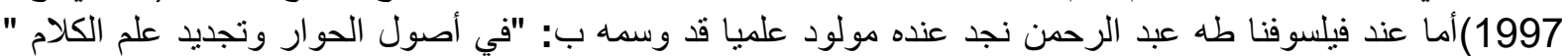
فهو يزيد تسميات أخرى ك: "علم النظر" أو "علم الاستدلال " و هذا ما نستشفه من قوله: "علم النظر أو علم الاستدلال

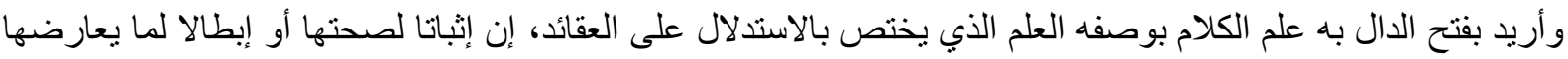

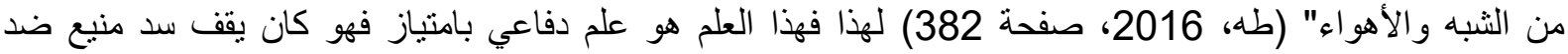

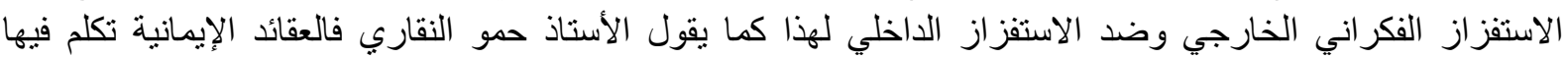
بمقتضيين اثثين: "مقتضى خارجي تمثل في الخصوم المعتقدين على حقائق مغايرة للحقيقة الإسلامية و المجتمعين عليها، الإنا

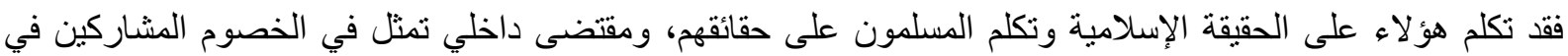

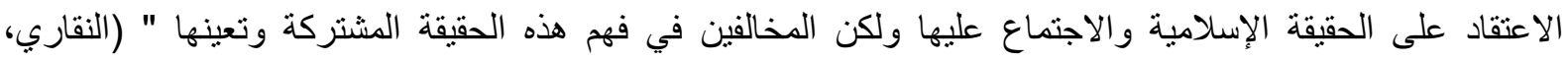
2010، صفحة 51) فهذا هو الحال عموما ما كان يطبع الجدالات و النقاثشات الكلامية الإسلامية.

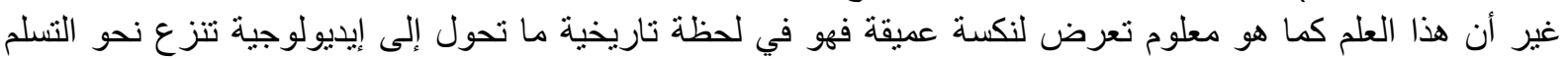

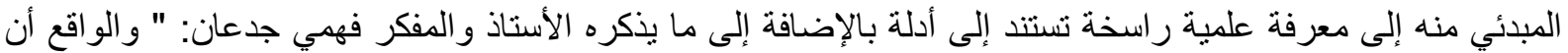
علم الكلام الكلاسيكي الذي خاض معارك مجيدة في وجه خصوم الإسلام وحفظ للعقيدة الإسلامية تماسكها وصر امتها 
المنطقية وأصولها الراسخة، قد كان عاجزا، في صورته المجردة الممنطقة، عن أن يقوم بلور حيوي فعال في الحياة الرياة

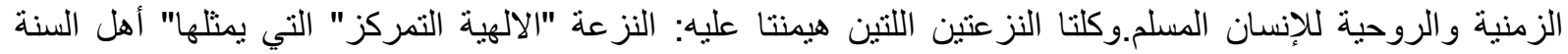

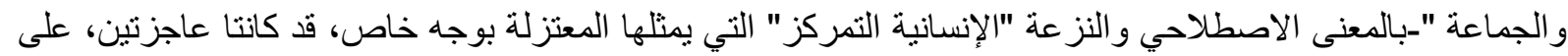

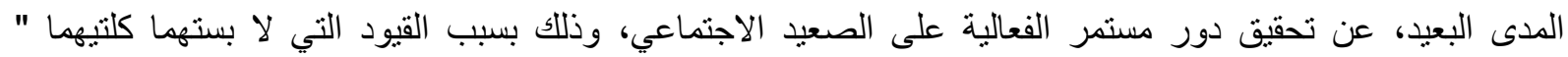

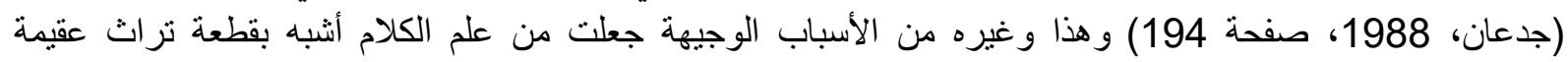

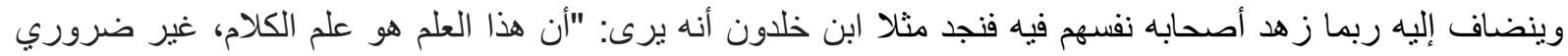

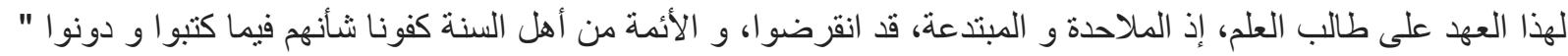

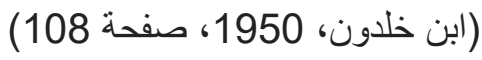

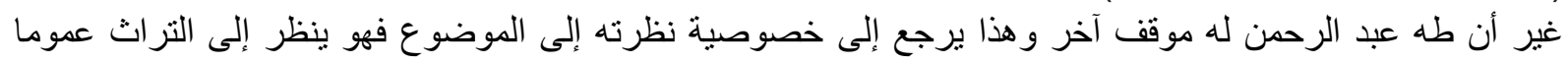

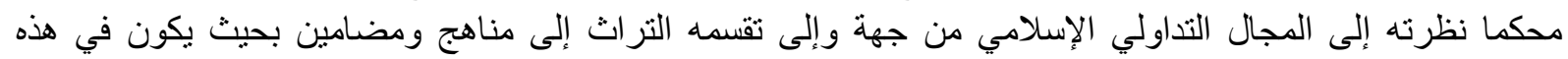

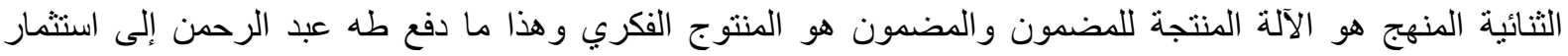

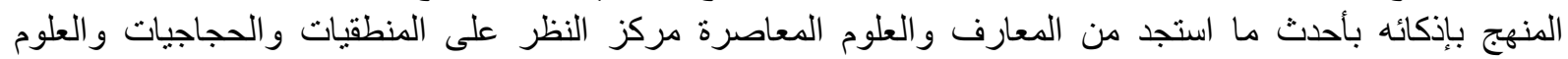

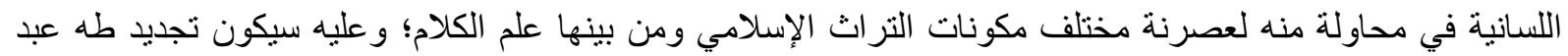

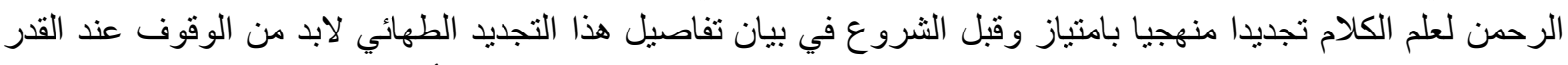

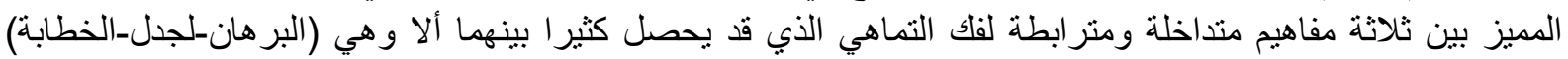
وذللك لتميز بين الاستدلال البرهاني الرياضي و الاستدلال الحجاجي الكلامي: نجمل ذلك في الجدول الآتي:

\begin{tabular}{|c|c|c|c|}
\hline الميزات & الفئه التي لمستئهدهه & العزض & الفن \\
\hline 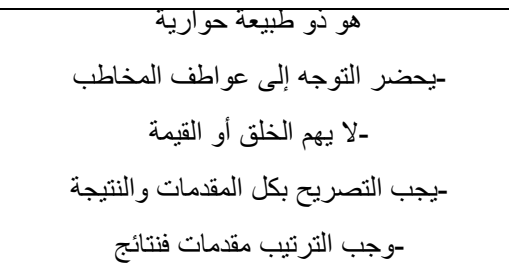 & و والو اضع طرفين /إلز إلز المدعي المعترض المبط & التنكييت و إحداث الإلزام & الجدل \\
\hline 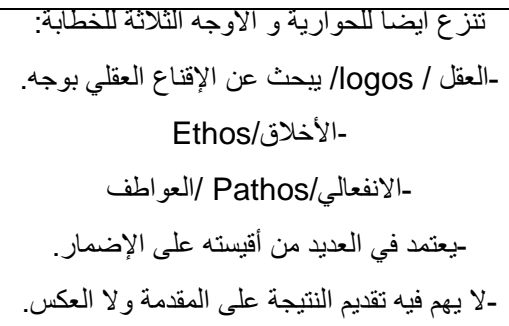 & جماعة ما لإحداث اعتقاد و عمل & الإقتاع "بإحداث اعتقاد ما & الخطابه \\
\hline 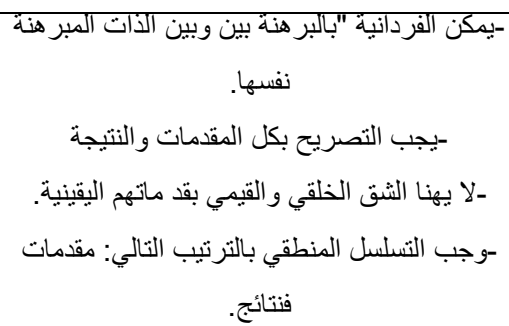 & لا تهمه الفئة. & البتر هنة اليقينية ودلكيل تلازز بين & البرهان \\
\hline
\end{tabular}

من خلال هذا الجدول تتضح الفروق الجوهرية بين ثلاثية الجدل و البرهان والخطابة وهذا ما يجعل العقلانية البرهانية

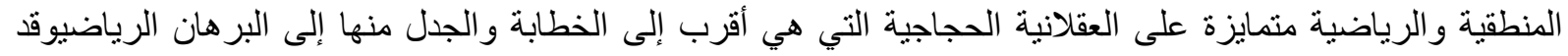

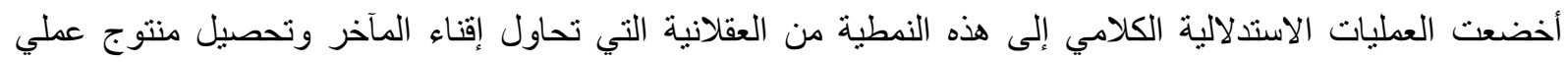

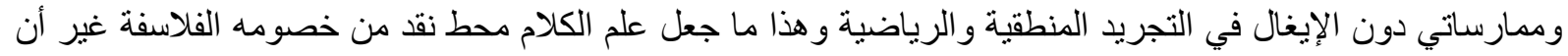

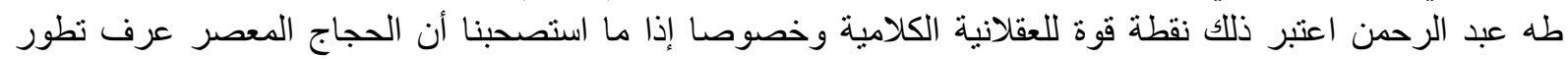

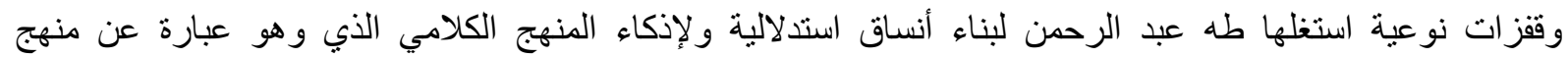

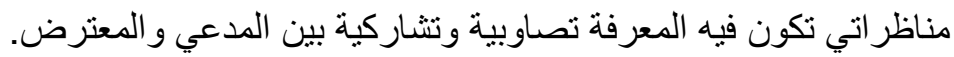


إن النظرة الخاصة التي يتسم بها المشروع الطهائي كما ذكرنا و التي تنم عن اطلاع عميق بمكنونات التراث الإن الإسلامي

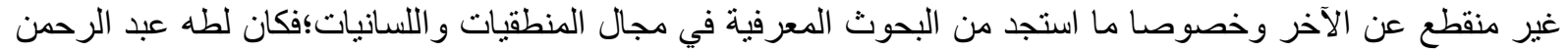
بعض المعالم الكبرى التي تأطر نظرته إلى المنهج الكلامي أو للمناظرة الكلامية يمكن أن نجمل بعضها فئا فيما يلي: 1- - حجاجية المقال القلسفي والكلامي:

لقد انطلق طه عبد الرحمن في دفاعه عن علم الكلام الإسلامي ضد خصومه التقليدين الفلاسفة بنقا عميق لقضية برهانية

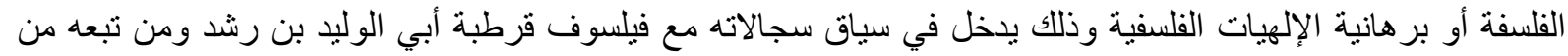

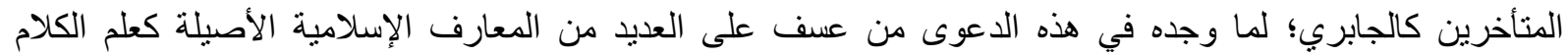

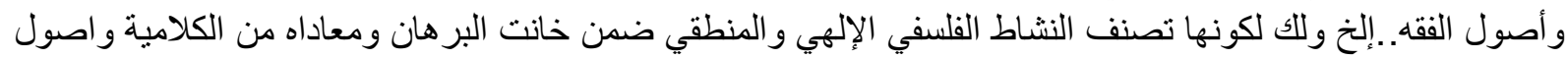

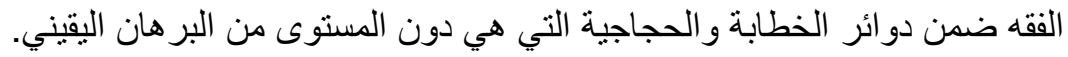

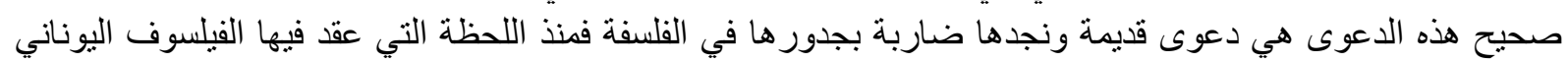

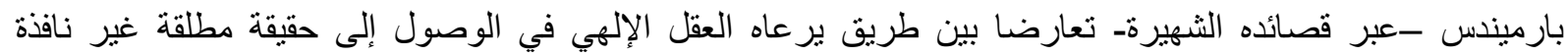

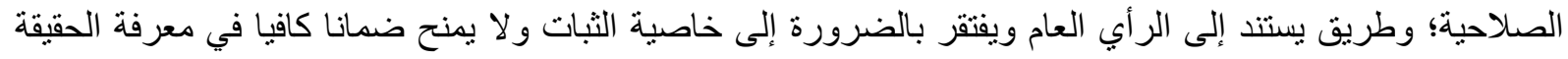

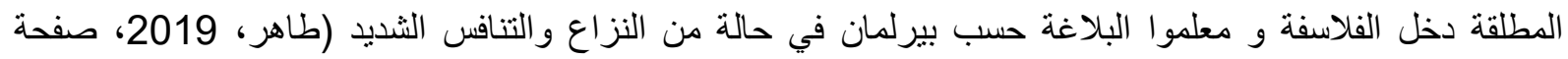

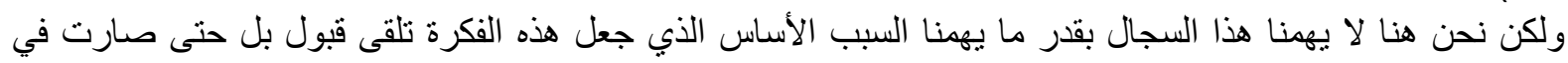

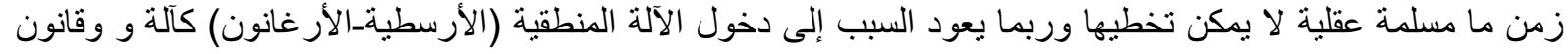

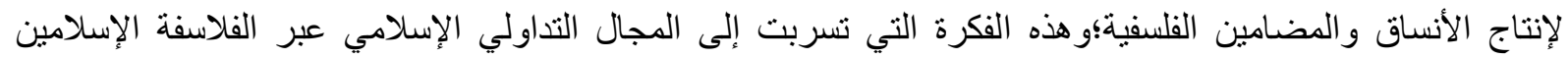

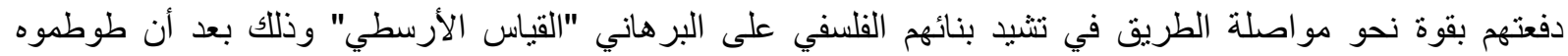

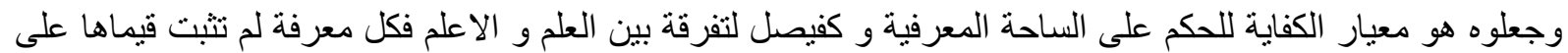

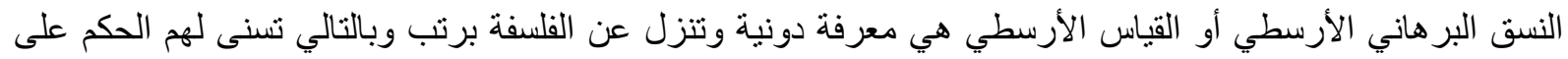

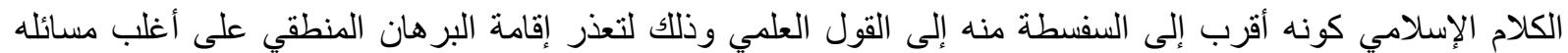

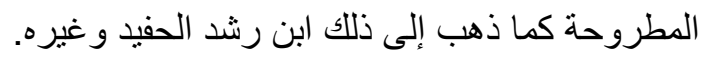

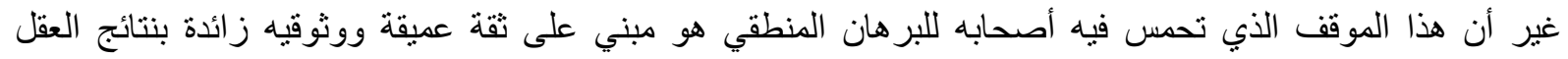

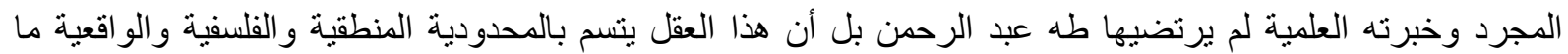

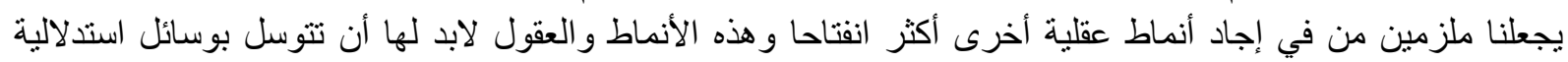

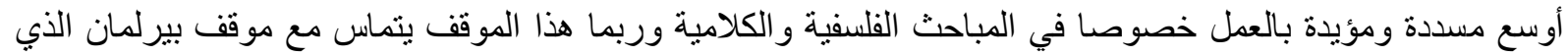

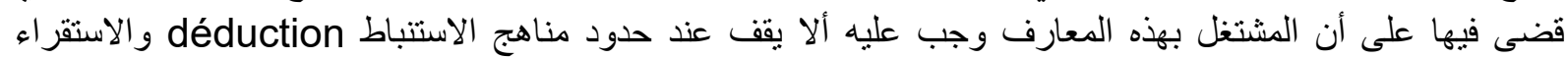

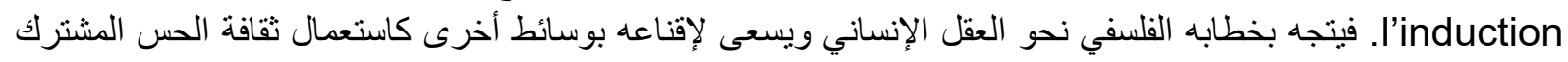

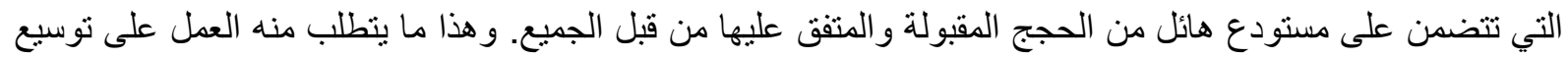

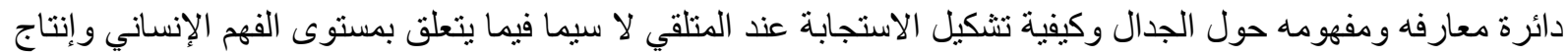
الحكم بخصوص القضايا المطروحة من خلال توضيح الخاصية العقلانية التي تتميز بها التقنيات الحجاجية البلاغية التهاية

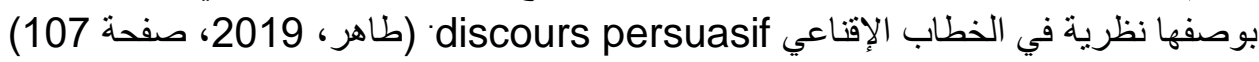

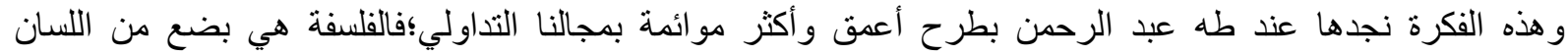

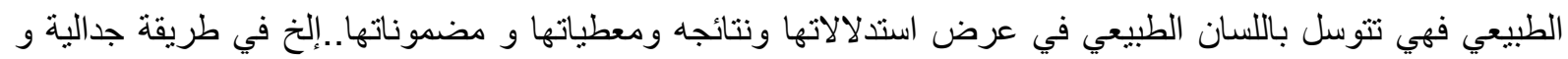

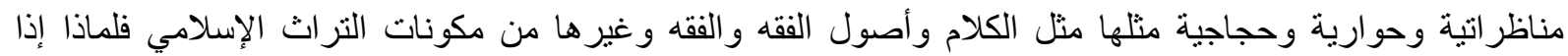

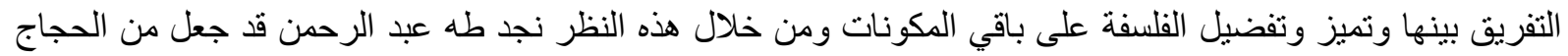

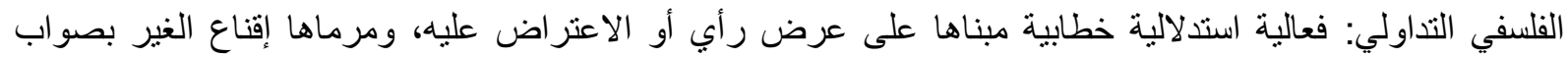

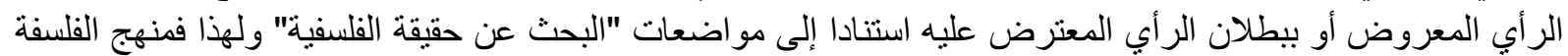

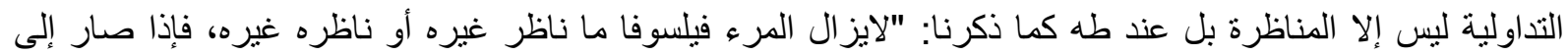

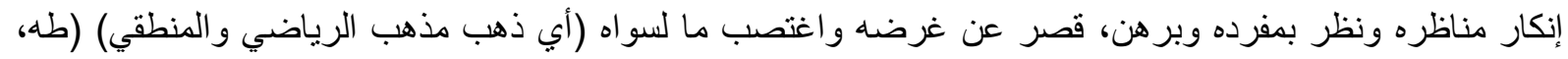

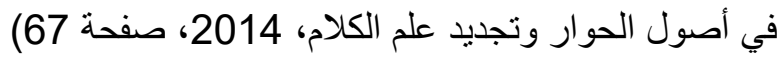


من المعالم الكبرى التي ينطلق منها طه عبد الرحمن في إعادته للمكون الحجاجي قضية التفريق بيناللغات الصورية

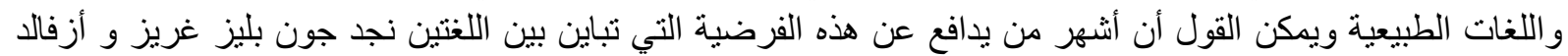

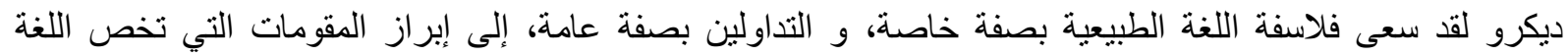

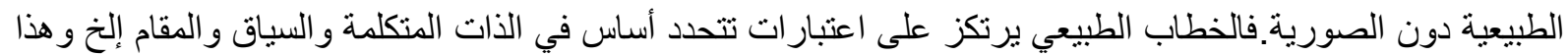

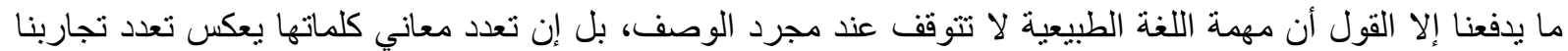

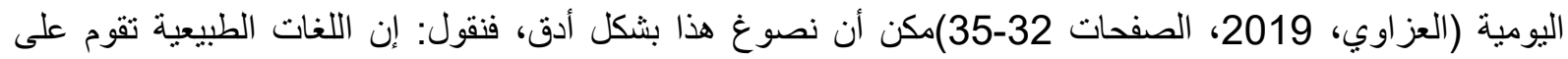
مجمو عة من المسلمات نوردها كالاتي: العيكات

- مسلمة الحوار: كل خطاب حوار كما يقول جان بليز غريز، وكل فعل كلامي هو حوار بين شخصين (المنكلم

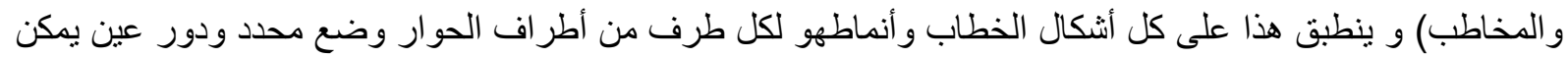
اعتبار أحدهما المتكلم والثاني المخاطب أو العارض في مقابل المعارض -opposant/ proposant-

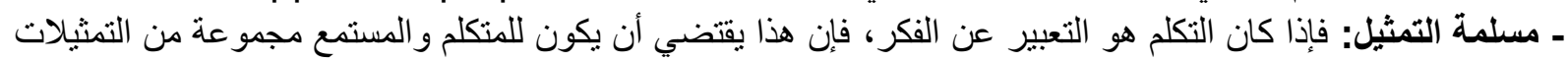

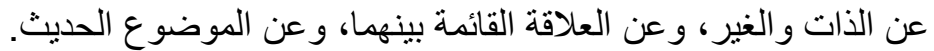
ـ مسلمة المركب الثقافي القبلي -le préconstruit culturel-: فاللغة الطبيعية ظاهرة ثقافية اجتماعية، ولهذا فإن التهان

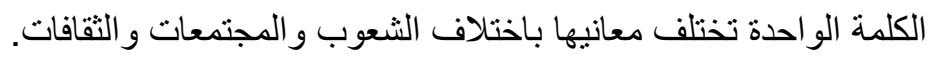

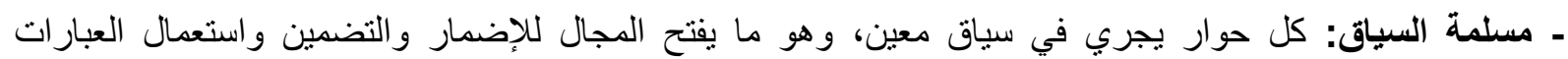
الإشارية.

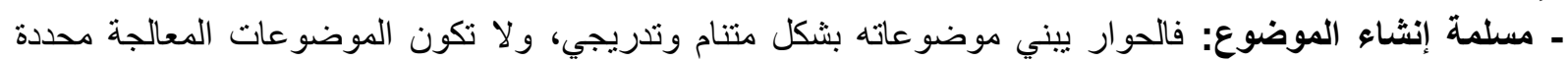

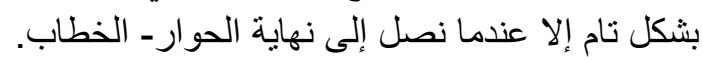

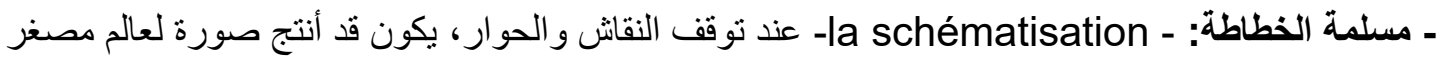
-micro-mondeيمكن إجمال الفروقة الصنئة الصيسية الجوهرية بين اللغات الصورية اللغات الطبيعية في الجدول الآتي (العزاوي، 2019، صفحة 35): صفي إحن

\begin{tabular}{|c|c|c|}
\hline اللغات الطبيعية & اللفات الصورية & 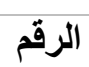 \\
\hline -وسيلة للإبداع وتمثيل المعارف. & -تعيد صياغة المعارف. & 1 \\
\hline -وسيلة للحوار بين متخاطبين. & ـو سيلة للحساب (غياب الذوات الفاعلة ). & 2 \\
\hline ـتشمل التضمينات (المركب الثقافي القبلي ). & ـ ـ ـل شيء فيها و اضح. & 3 \\
\hline ـ ـهناك فرق بين المعنى و الدلالة. & ـالمعنى و الدلالة شيء و احد. & 4 \\
\hline ــالموضو عات يتم إنشاؤ ها بشكل متتامي & ـالموضو عات فار غة أو محددة بشكل كلي منذ البداية. & 5 \\
\hline -يمكن استعمالها بمثابة ميتا لغة (اللغة الفوقية). & ـلا يمكن استعمالها بمثابة ميتا لغة (اللغة الفوقية). & 6 \\
\hline
\end{tabular}

يتضح لنا من خلال الخصائص المهمة التي طرحها غريز و غيره أن علم الكلام و الفلسفة؛ هي مباحث تنتمي إلى اللسان

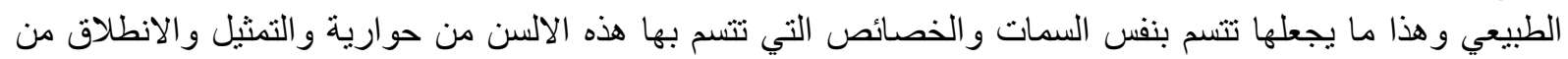
مجملة معار فة سابقة (المقام الاعتقادي ).

\section{3- 3 تعدية الحق وعلاقته بالمناظرة والحوارية:}

انطلاقا من مسلمة التكوثر العقل فالحقيقة العقلية هي حقيقة متكوثرة وليس هناك من يمنلك الحقيقة المطلقة بل الحقيقة هي

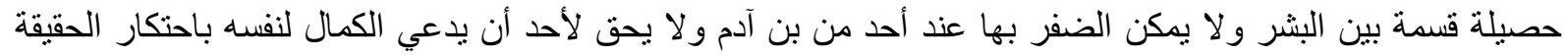

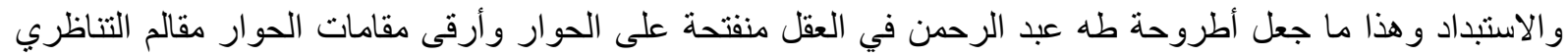

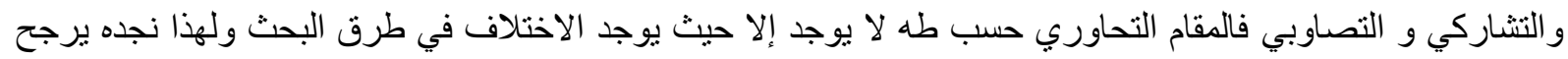

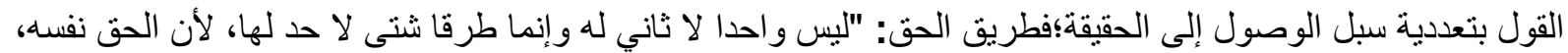




\section{TOWARDS A REHABILITATION OF THE HAJJAJLINGUISTIC COMPONENT \\ IN ISLAMIC SPEECH THOUGHT -THROUGH THE WRITINGS OF TAHA ABDEL- \\ RAHMAN}

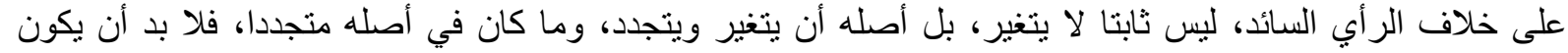

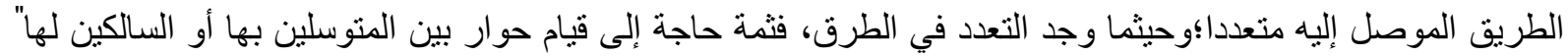

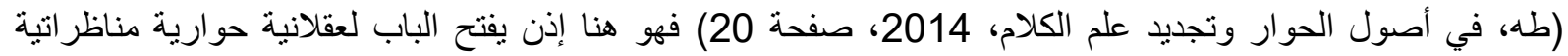

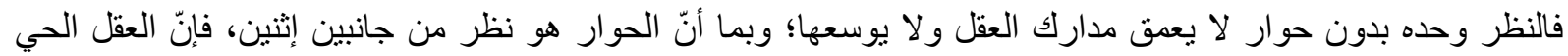

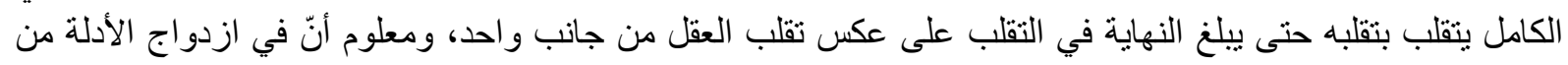

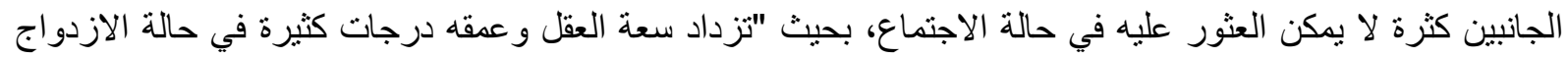

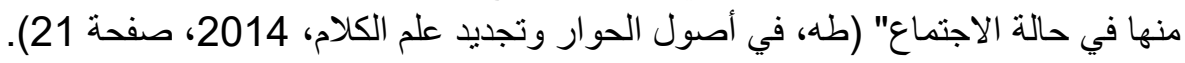

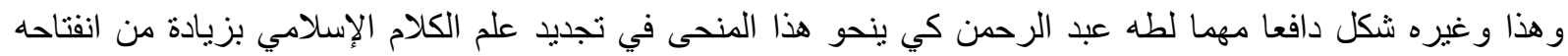

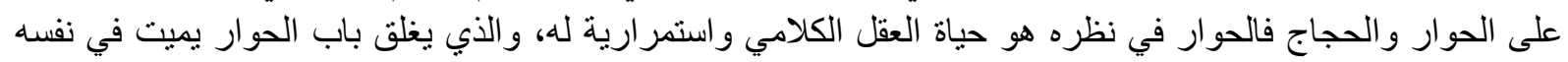

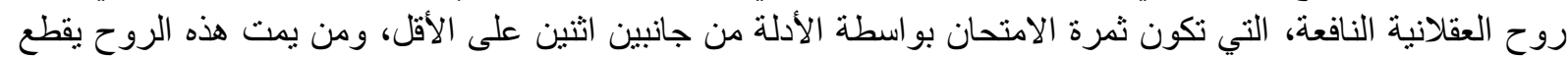

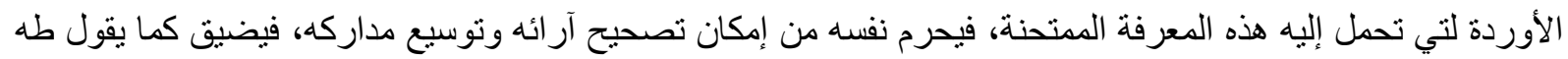

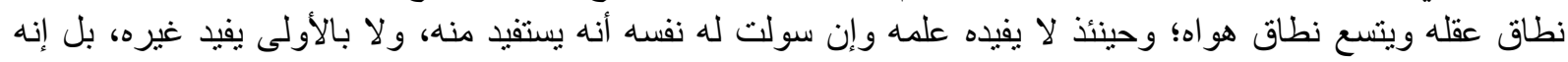

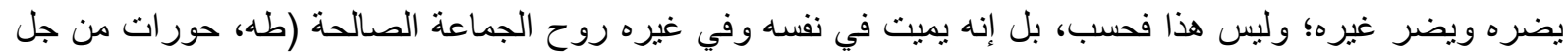

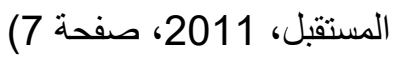

\section{المناظرة الكلامية كمنهج حجاجي أصيل:}

بدر اية عميقة بأهمية المنهج في تجديد التراث الإسلامي عموما وبعلم الكلام خصوصا يرى طه عبد الرحمن أن مناظرة

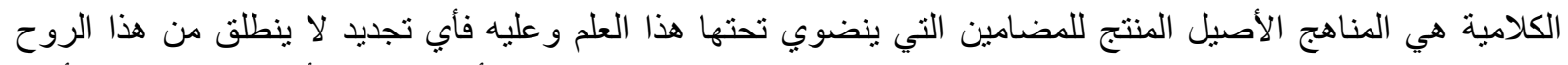

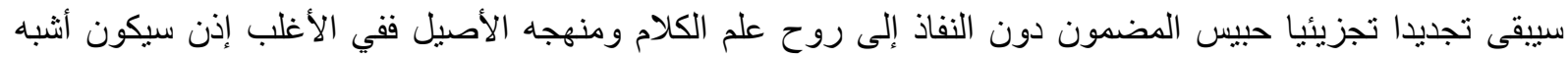

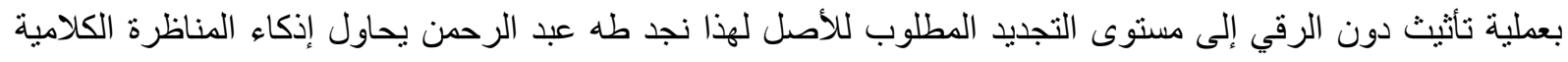

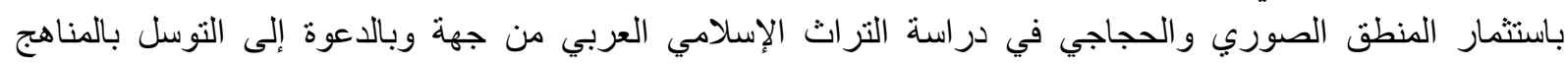

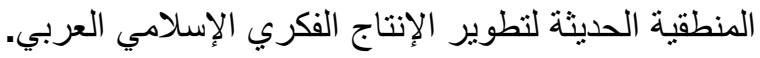

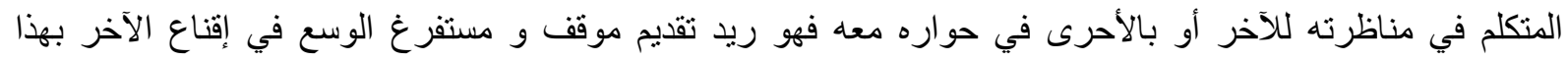

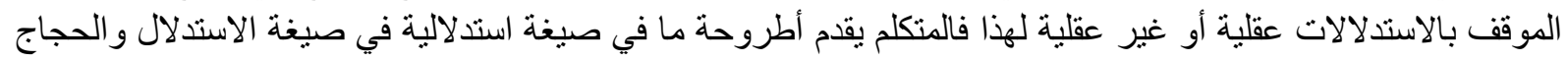

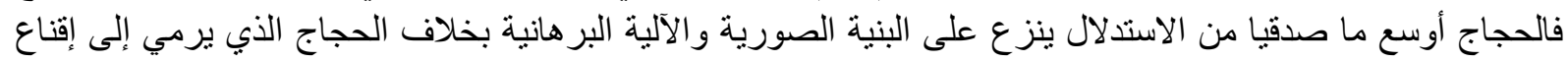

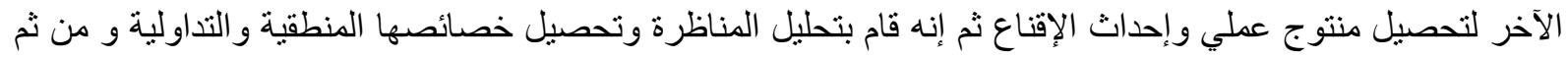

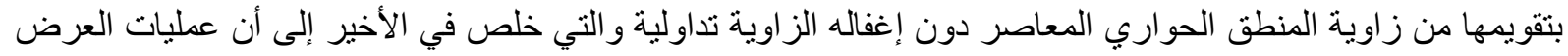

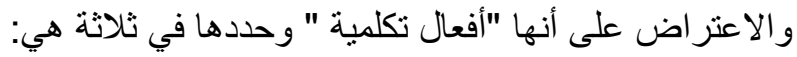

$$
\text { ج- أ-الادعاء. }
$$

أ- من شروط الادعاء:

- شرط أسبقية الاعتقاد وذلك بأن المدعي يعتقد صدق ما يدعي، ويطالب المخاطب بان يصدق بدوره هذه الدعوى؛وله بينه أو بينات على ما يدعي. - أن للمخاطب حق المطالبة بهذه البينات وتقويمها؛و أن يكون منطوق الادعاء أنه صادق ومفهومه أنه قابل للتكذيب،

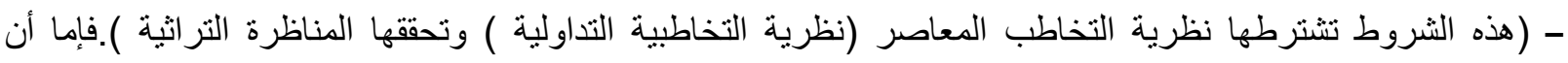
يكونوا قد أخذو ها من المناظرة أو أن المناظرة كانت سابقة لهذا التنظير (طه، في أصول الحوار وتجديد علم الكلام،

.(2014 


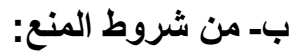

- أن يكون المنع: "فعلا تكلميا استجابيا إدباريا استشاريا تقويما تشكيكيا سجاليا ".

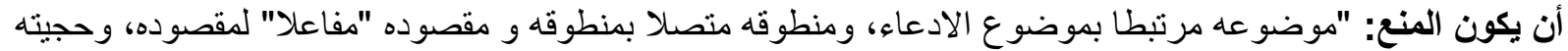
معاكسة في قوتها لحجية الادعاء و التدليل عليه مقيدا بالتدليل على الاديل الادعاء".

ت- من شروط التليل: (تم إذكائها بنظرية أفعال الكلامي نظرية جونسون ) 1- أن تكون الأدلة في صورة قضايا: شروط المضمون القضوي.

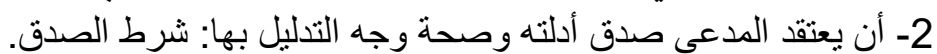

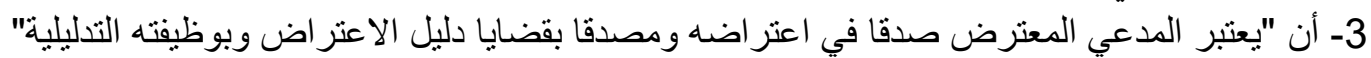

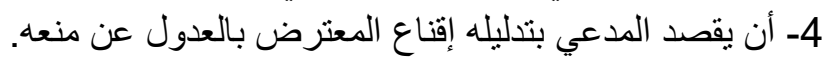

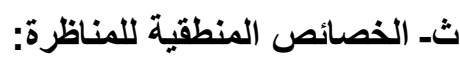

1- عرضها طه عبد الرحمن على شكل قو اعد عامة أكملية وقو اعد محددة لوظائف التناظرين.

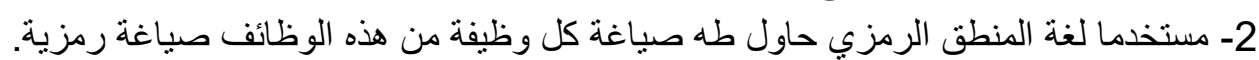

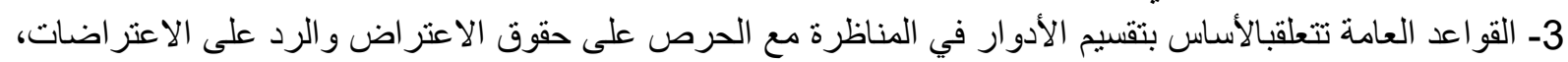

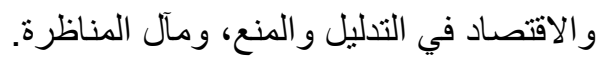

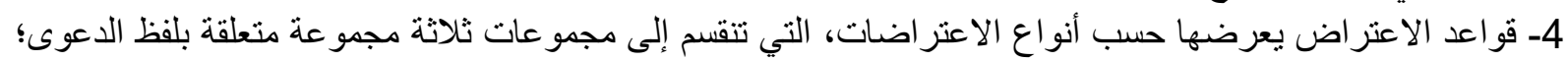

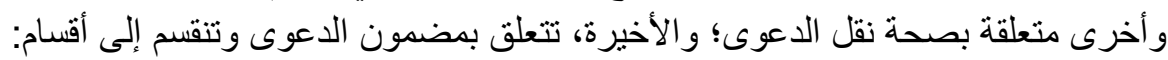

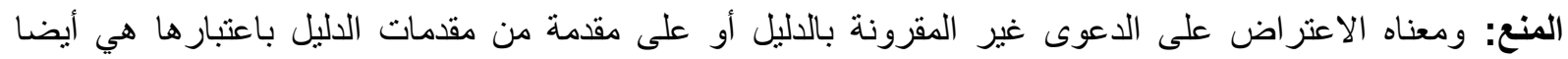

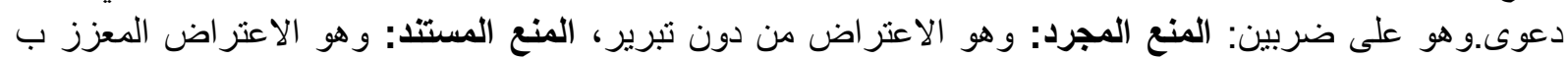

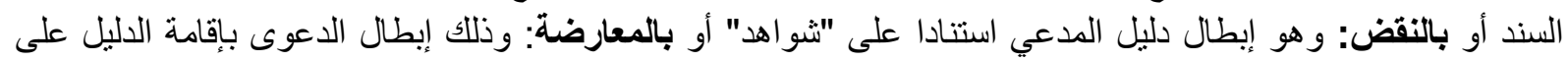

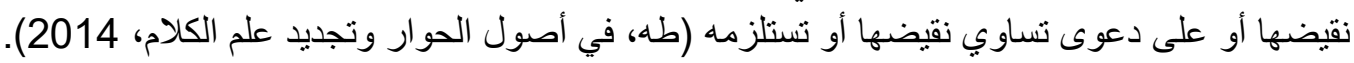

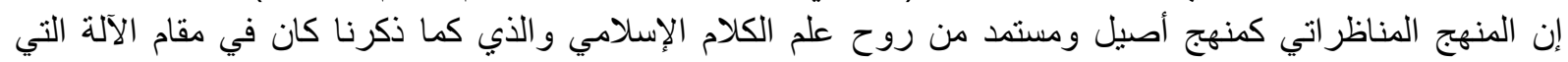

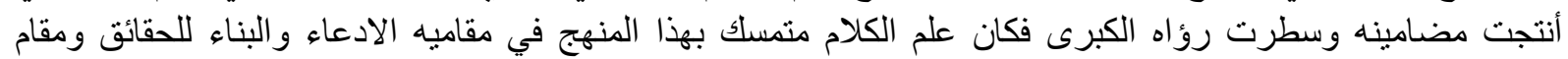

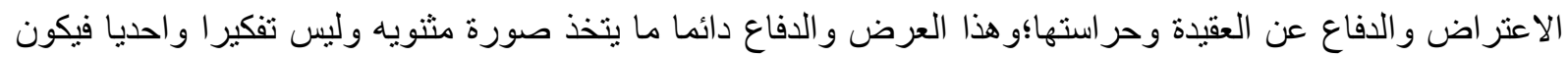

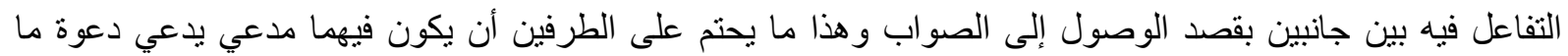

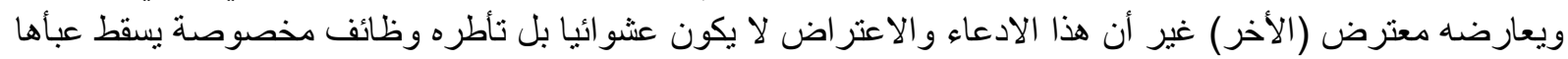

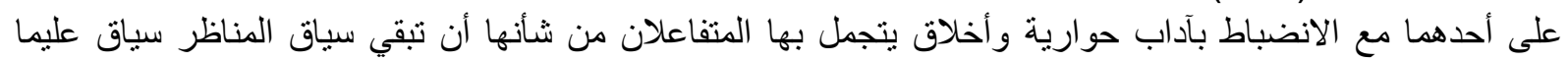

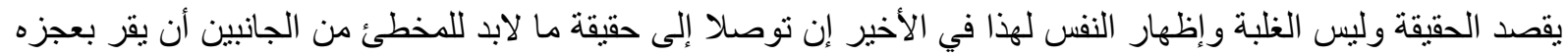
ويعترف بخطئه وير اجع أفكاره.

يذكرنا طه عبد الرحمن بالثروط الكبرى التي تأطر المناظرة وهي: -لابد لها من جانبين.

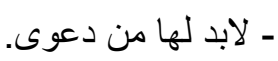
-لابد لها من مآل يكون بعجز أحد الجانبين.-لكل من الجانبين آداب ووظائف (طه، في أصول الحوار وتجديد علم الكلام، 


$$
\text { آليات الاستدلال الكلامي: القياس التمثيلي (الثاهد على الغائب ). }
$$

بالإضافة إلى المناظرة الكلامية يعتبر القياس التمثيل هو الاستدلال الذي يستخدم في العديد من الحوارات العقدية والكلامية

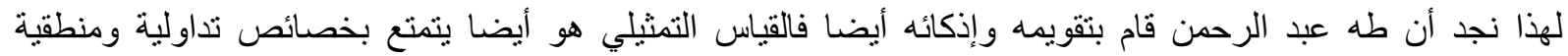

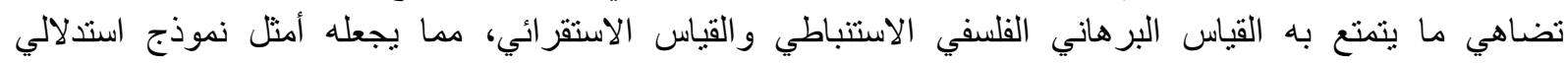

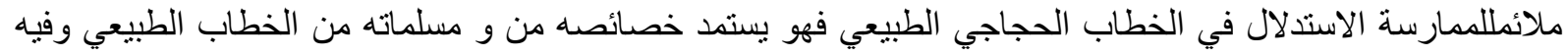

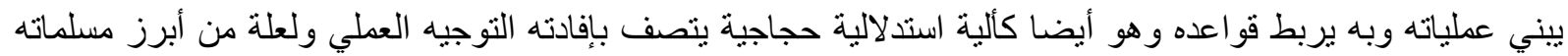

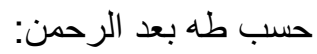

\section{1.التباسية الخطاب الطبيعي:}

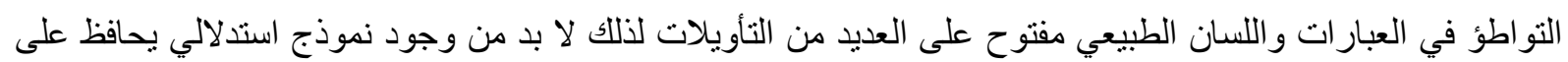

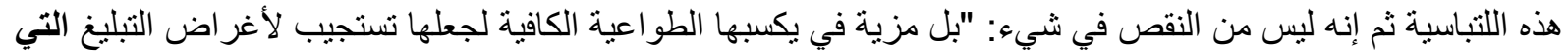

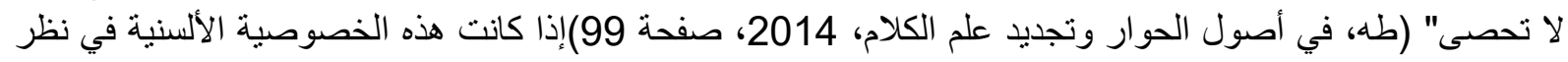

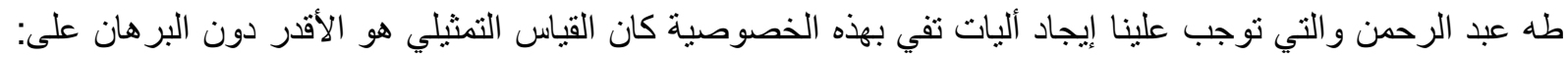

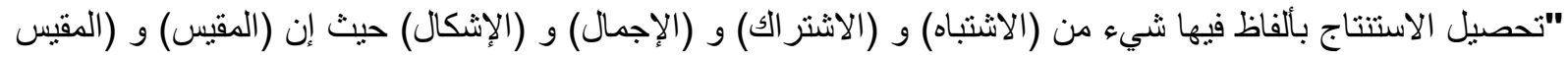

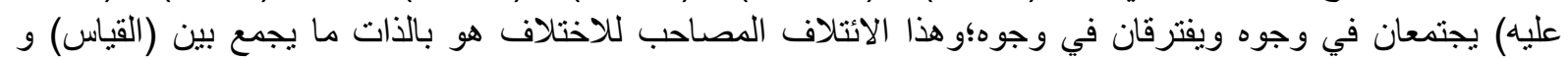

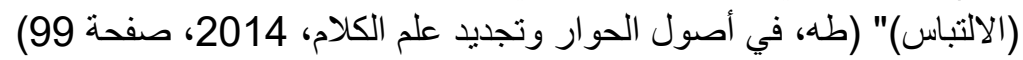

فهو يحتمل العرض والاعراض على خلاف القياس الصوري الالزامي فهو لا يحتمل العرض ولا الاعتر اض لكان لكون

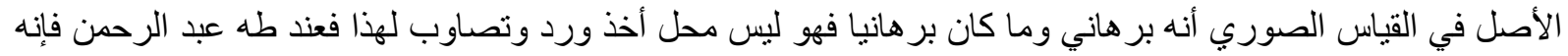

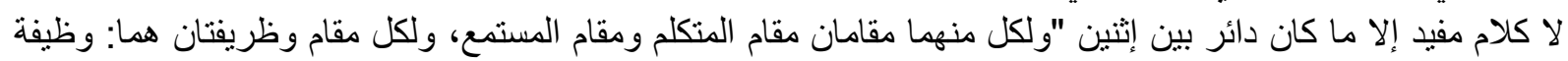

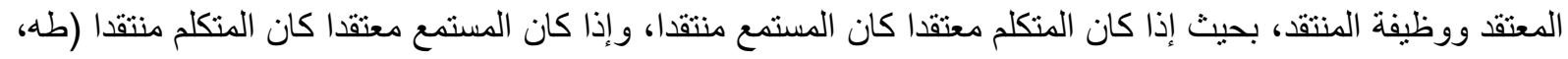

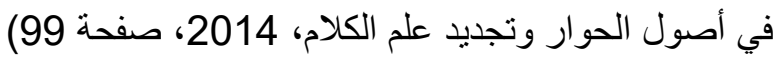

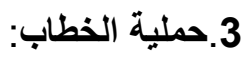

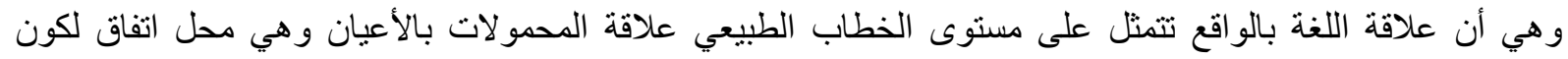

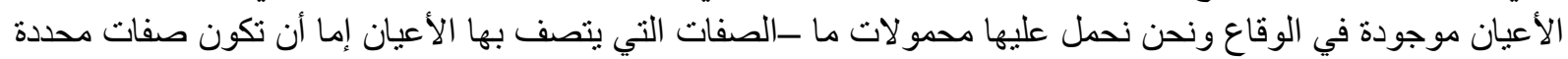

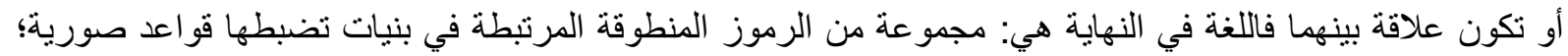

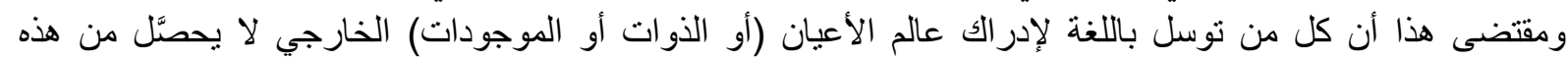

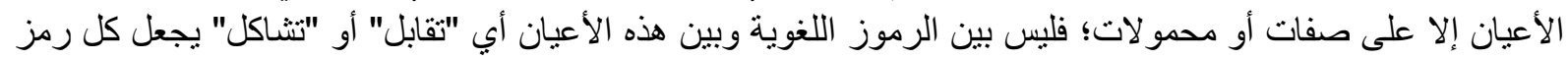

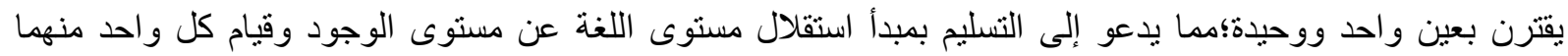
بشروط لا يشاركه فيها غيره (طه، في أصول الحوار وتجديد علم الكلام، 2014، صفحة الصنة 100) 4.مسلمة ترتيبية الصفات:

و هي أن علاقة الصفة بالموصوف تحتمل مر اتب متعددة لا يكون فيها الانطباق الكلي ولا عدمه إلا طرفيه المتباينين و هذا

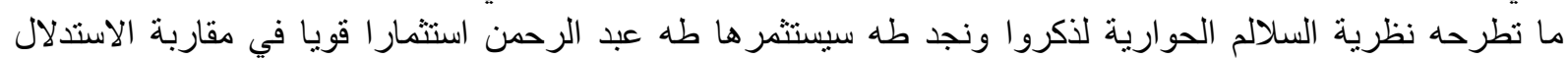

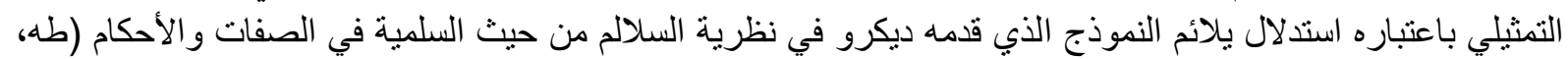

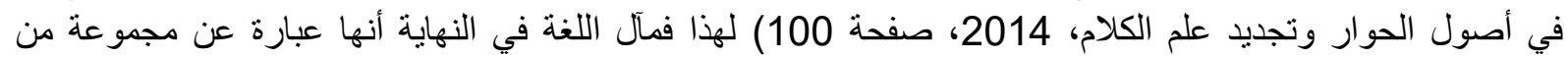

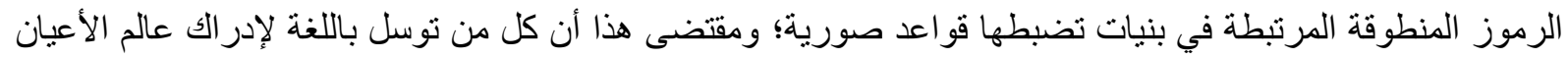

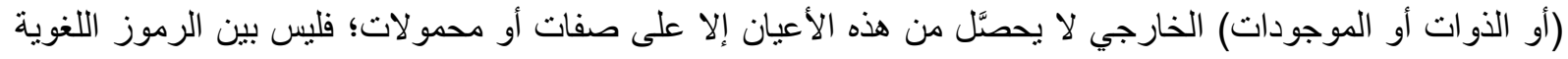

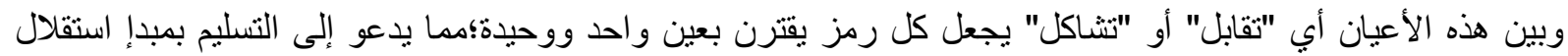

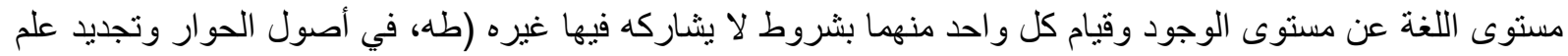

الكلام، 2014، صفحة 100) 
بـعمليات القياس: يعتمد القياس في تأطير تفاعلاته الاستدلالية على جملة من العمليات يجملها طه عبد الرحمن في ثلاثة عمليات أصلية:

ـعملية التفريق: وهي عملية استخر اج صفات الموضوع فهي في النهاية بمثابة عامل يدخل على الموضوع وينشئ له. صفات.

ـعملية الإثبات: وتتم برفع ونقل الصفة المفرقة الموصوف لتصير موصوفا بدور ها تستند إليها صفات خاصة بها.

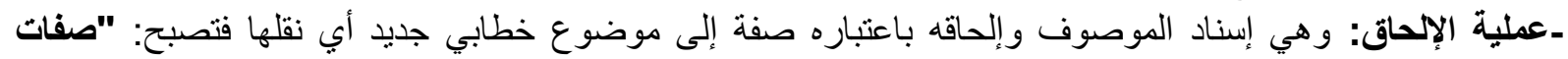

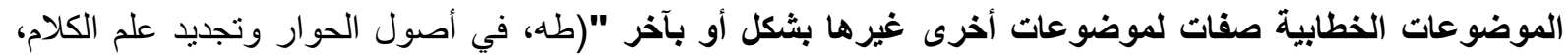

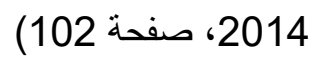
قوم طه عبد الرحمن وذكى القياس التمثيلي بنظريتين تداوليتين معاصرتين الاستلز ام التخاطبي (لجرايس h.p.grice)

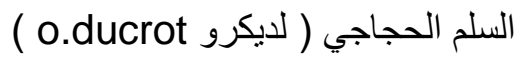
من خلال ما مر معنا يتجلى لنا أنه ليس من القبح أن نقول أن علم الكلام هو فعالية فلسفية أو أن نطلق عليه اسم الفلسفة

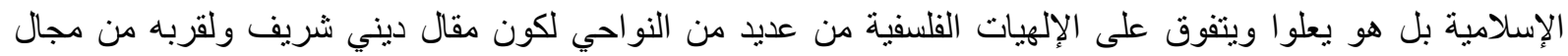

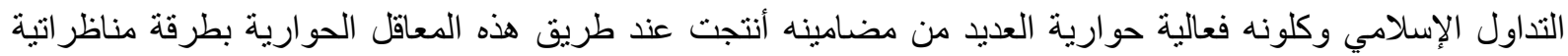

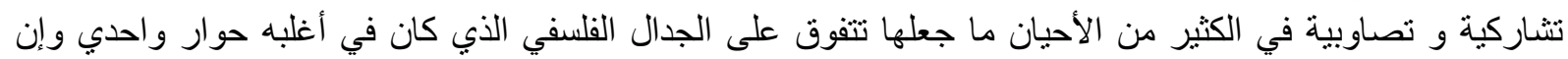

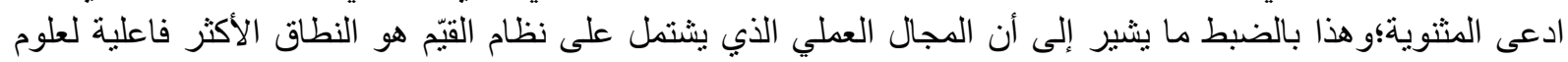

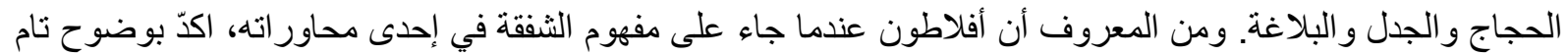

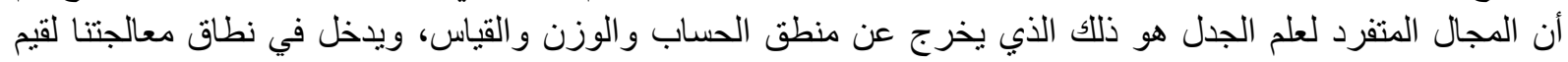

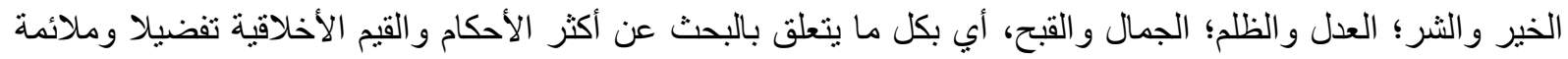

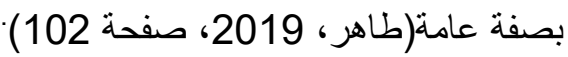

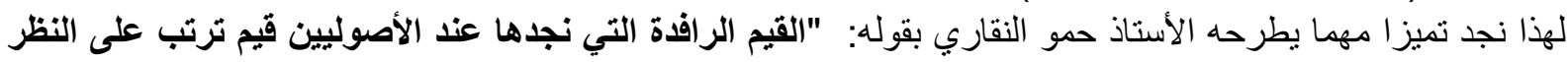

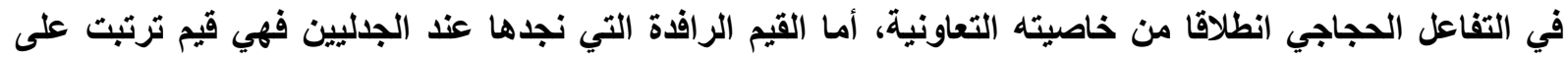

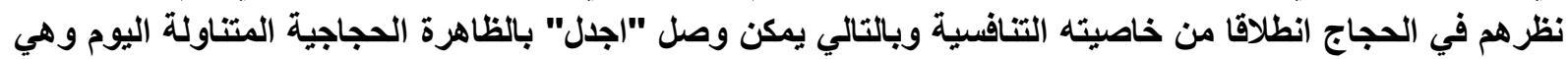

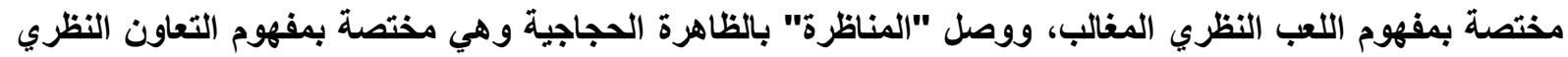

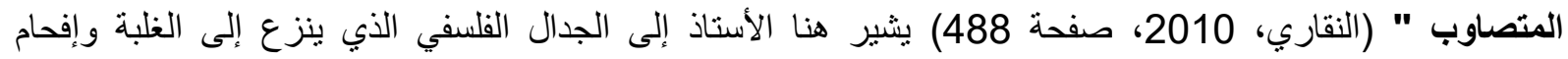

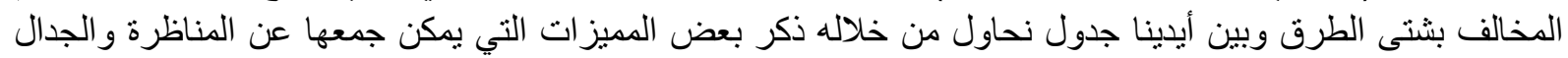

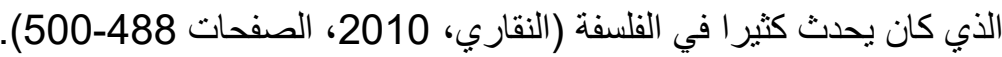

\begin{tabular}{|c|c|}
\hline الجدل الفلسفي & المناظرة الإسلامية (الكلامية و الأصولية) \\
\hline 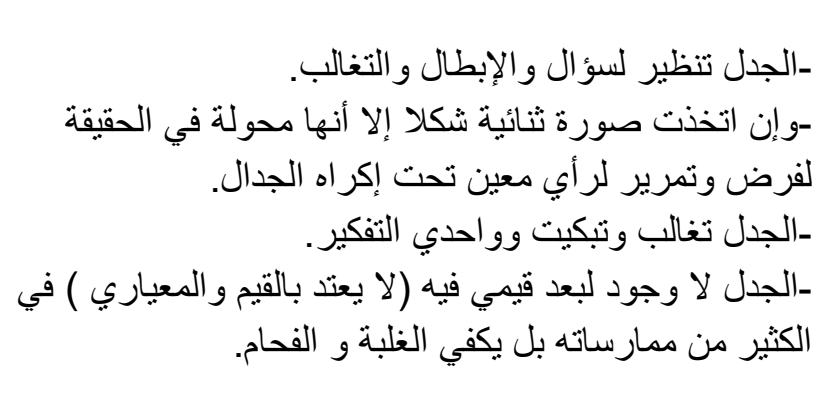 & 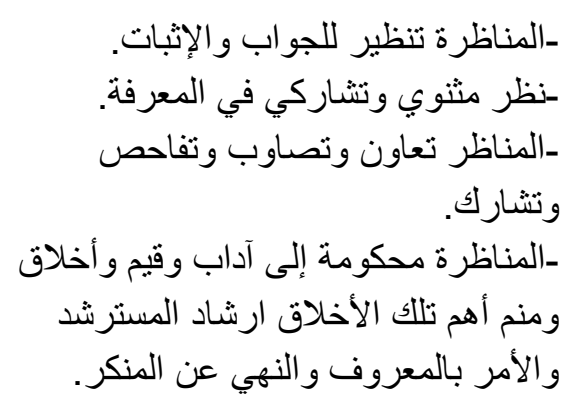 \\
\hline
\end{tabular}


من خلال هذه الإطلالة السريعة والمرور العجل على المشروع طه عبد الرحمن في تجديد المنهج الكلامي يمكن أن نخلص ببعض النتائج نجملها كالآتي:

ـ تجد طه عبد الرحمن هو تجديد منهجي من غير إهمال المضامين وذللك لأهمية القصوى التي يلعبها المنهج في إنتاج المضامين المعرفية فهو الآلة المنتجة وتجديدها يعطي حيوية وجدة لإعادة الدور الحضاري الذي كان يشغله الكلام الإسلامي في الدفاع عن الدين و القيم.

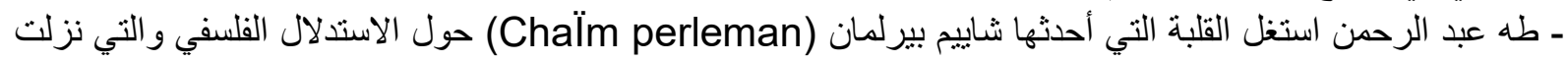
بدوائر الفلسفيات إلى المقام الحجاج ليطوى ردحا من الزمن كان تكرس فيه فكرة المفاضل والاستعلاء الفلسفي على

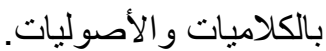
ـ المناظرة الكلامية هي المنهج الأصيل الذي كان يحكم مختلف التفاعلات المعرفية في المجال التداولي الإسلامي والآلة

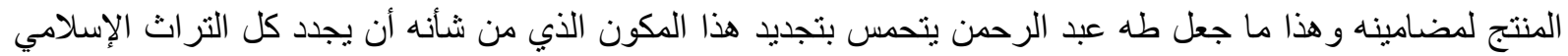

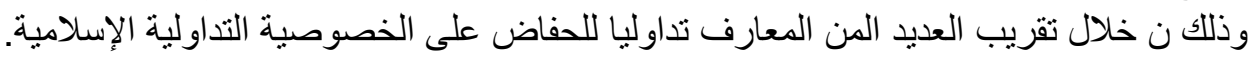

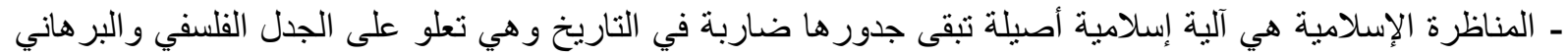

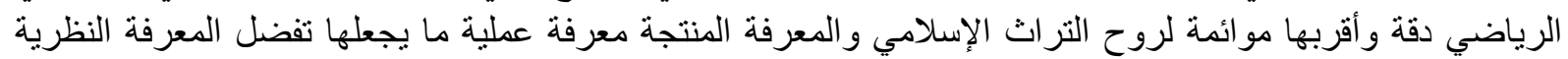
التي ينتجها البرهان و الجدل الفلسفي. ـ التباسية اللسان الطبيعي تحتم على المشتغلين في العلوم الدينية والعلوم الإنسانية إيجاد ألية هي اقرب من التحليل

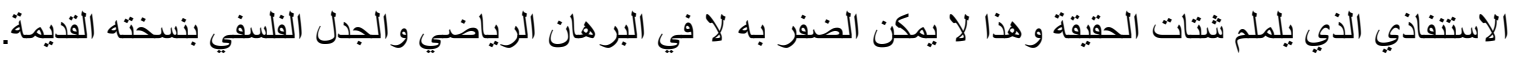

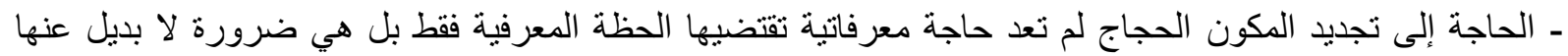

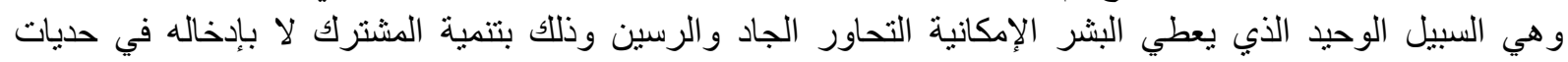

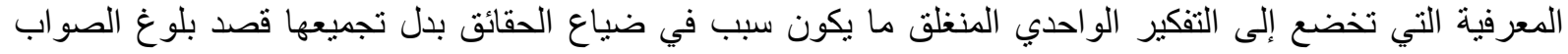
المطلوب.

قائمة المراجع والمصادر أبو بكر العزاوي. (2019). اللغة و المنطق در اسة في البناء و التأصيل. الأردن: عالم الكتب الحديث للنشر و التوزيع.

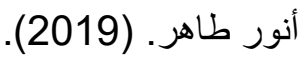
فلسفة الحجاج البلاغي نصوص مترجمة لثبييم بيرلمان. الأردن: عالم الكتب الحديث.

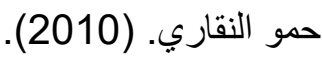
منطق الكلام. بيروت، لبنان: الدار العربية للعلوم ناشرون. عبد الرحمن طه. (2011). حور ات من جل المستقبل. بيروت، لبنان: الشبكة العربية للبحاث و النشر.

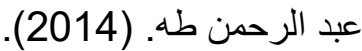
في أصول الحوار وتجديد علم الكلام. الدار البيضاء، المغرب: المركز الثقافي العربي.

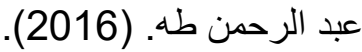
تجديد المنهج في تقويم التراث. الدار البيضاء، المغرب: المركز الثقافي العربي.

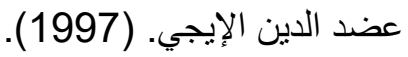
الموقف. بيروت، لبنان: دار الجيل. فهمي جدعان. (1988). أسس التقدم عند مفكري الإسلام. مصر : دار الثروق. 